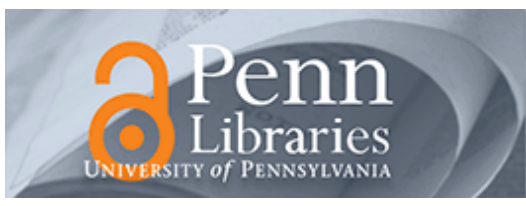

University of Pennsylvania ScholarlyCommons

Wharton Pension Research Council Working

Papers

Wharton Pension Research Council

$10-1-2007$

\title{
Optimal Life-Cycle Strategies in the Presence of Interest Rate and Inflation Risk
}

Raimond H. Maurer

Goethe University, RMAURER@WIWI.UNI-FRANKFURT.DE

Christian Schlag

Goethe University, schlag@finance.uni-frankfurt.de

Michael Z. Stamos

Goethe University, stamos@finance.uni-frankfurt.de

Follow this and additional works at: https://repository.upenn.edu/prc_papers

Part of the Economics Commons

Maurer, Raimond H.; Schlag, Christian; and Stamos, Michael Z., "Optimal Life-Cycle Strategies in the Presence of Interest Rate and Inflation Risk" (2007). Wharton Pension Research Council Working Papers. 260.

https://repository.upenn.edu/prc_papers/260

This paper is posted at ScholarlyCommons. https://repository.upenn.edu/prc_papers/260

For more information, please contact repository@pobox.upenn.edu. 


\title{
Optimal Life-Cycle Strategies in the Presence of Interest Rate and Inflation
} Risk

\author{
Abstract \\ Defined Contribution Plans
}

Keywords

Optimal Portfolio Choice, Life-Cycle Asset Allocation

\section{Disciplines}

Economics 


\title{
Optimal Life-Cycle Strategies in the Presence of Interest Rate and Inflation Risk
}

\author{
Raimond H. Maurer, Christian Schlag and Michael Z. Stamos
}

October 2007

\author{
PRC WP2008-01 \\ Pension Research Council Working Paper \\ Pension Research Council \\ The Wharton School, University of Pennsylvania \\ 3620 Locust Walk, 3000 SH-DH \\ Philadelphia, PA 19104-6302
}

Tel: 215.898.7620 Fax: 215.573.3418

Email: prc@wharton.upenn.edu

http://www.pensionresearchcouncil.org

\begin{abstract}
This research was conducted with support from the German Research Foundation (DFG) and the German Investment and Asset Management Association (BVI). Opinions and errors are solely those of the author and not of the institutions with whom the authors are affiliated. (c) 2007 R.H. Maurer, C. Schlag, and M.Z. Stamos. All Rights Reserved. All findings, interpretations, and conclusions of this paper represent the views of the author(s) and not those of the Wharton School or the Pension Research Council. (c) 2008 Pension Research Council of the Wharton School of the University of Pennsylvania. All rights reserved.
\end{abstract}




\title{
Optimal Life-Cycle Strategies in the Presence of Interest Rate and Inflation Risk*
}

\author{
Raimond H. Maurer
}

\author{
Christian Schlag
}

September 2007

\author{
Michael Z. Stamos
}

\begin{abstract}
The worldwide shift from public pay-as-you-go pension systems to privately funded pension schemes is accompanied by a huge increase in the households capital stock mounting to trillions of dollars worldwide which pour into defined contribution pension plans. In order to assess how these funds should be optimally invested, we derive the optimal time-dependent portfolio allocation strategy taking into account long-term stock market, term structure, and inflation risk. Our results confirm that the often advised so-called life-cycle strategy is optimal if non-financial wealth is taken into account. We also benchmark common longterm defined contribution asset allocation strategies relative to the optimum in order to the assess welfare implications for varying investment horizons and risk aversions. The outcome of utility heavily depends on whether the risk aversion of the investor is estimated appropriately. Misestimation of this parameter and hence wrong investment advice can lead to utility losses of around 60 percent in terms of certainty equivalent wealth.
\end{abstract}

JEL Codes: E21 G11 G23

Keywords: Optimal Portfolio Choice, Life-Cycle Asset Allocation, Defined Contribution Plans.

\footnotetext{
*Department of Finance, Goethe University (Frankfurt, Germany), e-mail: investment@finance.unifrankfurt.de, schlag@finance.uni-frankfurt.de, stamos@finance.uni-frankfurt.de. This research was conducted with support from the German Research Foundation (DFG) and the German Investment and Asset Management Association (BVI). Opinions and errors are solely those of the author and not of the institutions with whom the authors are affiliated.@2007 R.H. Maurer, C. Schlag, and M.Z. Stamos. All Rights Reserved.
} 


\title{
Optimal Life-Cycle Strategies in the Presence of Interest Rate and Inflation Risk
}

\author{
September 2007
}

\begin{abstract}
The worldwide shift from public pay-as-you-go pension systems to privately funded pension schemes is accompanied by a huge increase in the households capital stock mounting to trillions of dollars worldwide which pour into defined contribution pension plans. In order to assess how these funds should be optimally invested, we derive the optimal time-dependent portfolio allocation strategy taking into account long-term stock market, term structure, and inflation risk. Our results confirm that the often advised so-called life-cycle strategy is optimal if non-financial wealth is taken into account. We also benchmark common longterm defined contribution asset allocation strategies relative to the optimum in order to the assess welfare implications for varying investment horizons and risk aversions. The outcome of utility heavily depends on whether the risk aversion of the investor is estimated appropriately. Misestimation of this parameter and hence wrong investment advice can lead to utility losses of around 60 percent in terms of certainty equivalent wealth.
\end{abstract}

JEL Codes: E21 G11 G23

Keywords: Optimal Portfolio Choice, Life-Cycle Asset Allocation, Defined Contribution Plans. 


\section{Introduction}

The worldwide shift from pay-as-you-go to privately funded pension systems accompanied with the swing from defined benefit schemes to defined contribution plans transfer both investment risks and responsibility to millions of individual investors. From the perspective of private investors choosing the right asset allocation seems to be an onerous task. For instance, Rooij, Kool, and Prast (2007) find in an empirical analysis that households consider themselves financially unsophisticated and are not willing to take control over their retirement assets. $1^{1}$ According to Huberman, Iyengar, and Jiang (2004) there exists a strong negative correlation between the number of funds offered in self directed $401(\mathrm{k})$ pension plans and the $401(\mathrm{k})$ participation rate. Since individual plan participants do not seem to understand the risks associated with the various asset allocation options the present paper aims to derive optimal asset allocation rules which could serve as default options for defined contribution plans. Beshears et al. (2006) find a tremendous impact of default options on the outcome of retirement wealth since financially unsophisticated investors stick to the default option to circumvent serious investment mistakes.

The default portfolio strategy has to be adequate for a broad range of participants from a welfare perspective and feasible from the viewpoint of pension plan providers such as banks, insurance companies, mutual funds, and employers. In order to be practicable to implement from the plan provider perspective we impose that the optimal investment strategy only depends on the age and the risk aversion of the plan participant. Such a life-cycle strategy seems to be appealing for a variety of reasons. The simplicity ensures that administrative costs of the plan sponsor are small even if it is implemented for a large number of plan participants. Further, transaction costs are

\footnotetext{
${ }^{1}$ Also psychological studies by Tversky and Shafir (1992), Shafir, Simonson, and Tversky (1993) as well as Iyengar and Lepper (2000) which report that households are inclined to postpone decision making when the complexity of tasks rises.
} 
kept at a minimum and excessive active trading is avoided.2 From the view of plan participants the static life-cycle strategy is transparent and easily comprehensible since they ex-ante know which asset allocation will be held at future dates. As a result, participants can also easily compare different static life-cycle strategies. Life-cycle mutual funds are one of the most successfully growing segments of the mutual fund industry in the U.S. The assets under management have grown rapidly from $\$ 1$ billion in 1996 to $\$ 120$ billion in 2006 (Viceira, 2007). Remarkably, president George W. Bush has outlined a plan in which workers can invest a portion of their payroll taxes into personal accounts in exchange for a cut in Social Security benefits. One investment option of these personal accounts is the life-cycle portfolio.

We have to mention that recent theoretical portfolio choice studies document that rational investors should trade actively according to stochastic changes of the investment opportunity set [ $^{3}$ Cairns, Blake, and Dowd (2006) specifically derive the optimal dynamic asset allocation for defined contribution plans. The derived stochastic life-cycle strategy exhibits large fluctuations in asset weights over time since hedge demands are reacting commensurately to the stochastically varying investment opportunity set. It also exhibits high leveraged stock positions in the beginning of the accumulation plan since rational investors perceive their human capital as an implicit bond portfolio. The study also finds that a static life-cycle strategy is significantly suboptimal compared to its stochastic counterpart. Cocco, Gomez, and Maenhout (2005) provide contradictory theoretical evidence that utility losses of static life-cycle strategies are vary small compared to the dynamic optimum even theough they do not optimize the static life-cycle rule. After all, it also seems doubtful whether individual pension plan participants are

\footnotetext{
${ }^{2}$ Barber and Odean (2000) find empirical evidence that active trading reduces the investment performance of households substantially due to transaction costs and Carhart (1997) finds the same result for actively managed mutual funds.

${ }^{3}$ For instance, the impact of interest rate risk on hedge demands has been analyzed by Brennan and Xia (2000) and by Wachter (2003), risky inflation by Campbell and Viceira (2001) and Brennan and Xia (2002), and for changing risk premiums see Brandt (1999), Campbell and Viceira (1999), Wachter (2002), and Campbell, Chan, and Viceira (2003).
} 
qualified enough to understand optimal stochastic asset allocation strategies and are willing or allowed to invest into highly leveraged stock portfolios. Another strand of literature explores the risks associated to typical life-cycle asset allocations rules by simulating the outcome of retirement wealth via historical simulations. Poterba et al. (2005) use historical simulations to draw the distribution of 401(k) retirement wealth for a large number of households and Shiller (2005) uses 134 years of stock return data for various countries to simulate the outcome of life-cycle personal accounts.

While previous studies did not optimize the static life-cycle asset allocation rules explicitly we show how static life-cycle strategies can be optimized in a model with stochastically varying investment opportunity set. We set up a continuous time asset model which reasonably captures the empirical evidence of multi decade stock market, interest rate and inflation rate movements and derive the optimal investment schemes for CRRA plan participants which contribute a certain fraction of their labor income to a pension plan. Since the resulting static life-cycle strategy evolves deterministically over time it somehow captures the average development of the investment opportunity set over time but not the actual state of nature. The strategy exhibits declining equity exposures until retirement, so as to maintain the optimal stock fraction of total wealth which includes financial wealth and the present value of future contributions. This result conforms to recent life-cycle asset allocation studies (e.g. Cocco, Gomes, and Maenhout, 2005) and is similar to popular life-cycle rules suggested by financial advisors or finance books (Malkiel, 1996).

In order to evaluate the risk associated to the derived optimal static life-cycle strategies we conduct a Monte Carlo analysis to derive distributional properties of terminal wealth in real terms and of equivalent annuities payments assuming that terminal wealth is converted into a life-annuity at retirement age. We use the optimal strategy as a benchmark in order to compare long term investment schemes typically found in practice such as the constant mix strategy, the "100-age" life-cycle rule, and the static as 
well as dynamic portfolio insurance strategies. This allows us to assess the degree of efficiency of these investment schemes compared to the optimal life-cycle strategy. To this end, we perform a welfare analysis based on Monte Carlo sampling for the various strategies, ages, and risk aversions.

The remainder of the paper is structured as follows. In Section 2 we describe the asset model, its calibration, and derive the wealth evolution equation. Section 3 derives and discusses the optimal life-cycle strategy. In Section 4 we conduct a Monte Carlo analysis in order to create projections about potential outcomes of terminal wealth and pension income. A welfare analysis is also undertaken to compare various practicable asset allocation strategies relative to the optimum, before Section 5 concludes.

\section{The Asset Model}

\subsection{Stock and Bond Market}

This section is concerned with the main long term investment risk factors which private investors have to cope with: stock market price risk, interest rate risk, and inflation risk. All considered risk factors are captured by separate stochastic diffusion processes, each of which can be potentially correlated. The value of the stock market $S$ is assumed to evolve according to

$$
d S_{t}=\left(r_{t}+\sigma_{s} \lambda_{s}\right) S_{t} d t+\sigma_{s} S_{t} d Z_{t}^{S},
$$

where $r_{t}$ denotes the short nominal interest rate, $\sigma_{s}$ is the instantaneous standard deviation of stock returns, $\lambda_{S}>0$ represents the market price of equity risk, and $Z^{S}$ is a Wiener process. So, we assume that the instantaneously expected stock return is the sum of the prevailing interest rate and the constant risk premium. This way of modeling ensures that the expected stock return never drops below the risk-free interest rate. 
The continuous nominal short rate process is given by Vasiceks (1977) term structure model

$$
d r_{t}=\kappa_{r}\left(\theta_{r}-r_{t}\right) d t+\sigma_{r} d Z_{t}^{r}
$$

where $\theta_{r}$ denotes the long run mean, $\kappa_{r}$ represents the parameter of mean reversion and $\sigma_{r}$ is the volatility of the short rate. Mean reversion gives the interest rate a tendency to move back to the long run mean $\theta_{r}$, where the speed factor $\kappa_{r}$ indicates how strong the force of mean reversion is. The increments of the standardized Wiener processes $d Z_{t}^{r}$ and $d Z_{t}^{S}$ are instantaneously correlated with $\rho_{S r}$, which reflects the empirical evidence of interdependencies between stock returns and interest rates. The value process of the money market account $K_{t}$ is given by

$$
d K_{t}=r_{t} K_{t} d t .
$$

To model the dynamics of the bond portfolio, we take advantage of the direct relation between the movements of the risk-free term structure and bond returns. The dynamics of the value of the risky bond portfolio $B$ with a given modified duration $D=\frac{\partial B}{\partial r} \frac{1}{B}$ follow endogenously from the assumption of the Vasicek model with

$$
d B_{t}(D)=\left(r+\sigma_{B}(D) \lambda_{r}\right) B_{t} d t-\sigma_{B}(D) B_{t} d Z_{t}^{r}
$$

where $\lambda_{r}>0$ is the market price of interest rate risk and $\sigma_{B}(D)=\sigma_{r} D$ is the instantaneous volatility of the bond portfolio. 4 Again, the expected return of risky bonds will always be higher than the current riskless interest rate. For the correlation between stocks and bonds it holds that $\rho_{S B}=-\rho_{S r}$. The (instantaneous) variance-covariance

\footnotetext{
${ }^{4}$ The same approach to model the price process of a bond portfolio is used by Munk, Srensen, and Vinther (2004).
} 
matrix of stocks and bonds is therefore given by

$$
\Sigma=\left(\begin{array}{cc}
\sigma_{S}^{2} & \sigma_{S} \sigma_{B} \rho_{S B} \\
\sigma_{S} \sigma_{B} \rho_{S B} & \sigma_{B}^{2}
\end{array}\right)
$$

The term structure of zero bond prices in $t$ with maturities $\tau>0$ is given by

$$
P(t, t+\tau)=e^{-a(\tau)-b(\tau) r_{t}}
$$

with

$$
\begin{aligned}
a(\tau) & =R(\infty)(\tau-b(\tau))+\frac{\sigma_{r}^{2}}{4 \kappa} b(\tau)^{2}, \\
b(\tau) & =\frac{1}{\kappa}\left(1-e^{-\kappa \tau}\right), \\
R(\infty) & =\theta+\frac{\sigma_{r} \lambda_{r}}{\kappa}-\frac{1}{2} \frac{\sigma_{r}^{2}}{\kappa^{2}}
\end{aligned}
$$

where $R(\infty)$ denotes the nominal interest of a zero bond with infinite maturity. Depending on the parameter, the Vasicek term structure model can reproduce all types of empirically observed term structures, i.e. normal, inverse and humped.

\subsection{Inflation Risk}

We model the inflation rate explicitly because the effect of uncertain inflation becomes especially important when we consider multi-decade investment horizons. We assume that the nominal price level of the consumption good evolves according to

$$
d Q_{t}=i_{e, t} Q_{t} d t+\sigma_{Q} Q_{t} d Z_{t}^{Q}
$$

with $i_{e, t}$ as the expected rate of inflation an $\sigma_{Q}$ the volatility of the unexpected inflation. The change in the price of the consumption good is correlated with the stock price and 
the interest rate with $\rho_{S Q}$ and $\rho_{r Q}$, respectively. The expected inflation rate itself is assumed to follow the Ornstein-Uhlenbeck process

$$
d i_{e, t}=\kappa_{i}\left(\theta_{i}-i_{e, t}\right) d t+\sigma_{i} d Z_{t}^{i}
$$

where $\theta_{i}$ describes the long run mean, $\kappa_{i}$ represents the degree of mean reversion, and $\sigma_{i}$ the volatility of the inflation rate. The correlations between $d Z_{t}^{S}, d Z_{t}^{r}, d Z_{t}^{Q}$ and $d Z_{t}^{i}$ are denoted by $\rho_{S i}, \rho_{r i}$, and $\rho_{Q i}$. This way of modeling the price process of the consumption good reflects that expected inflation rates are mean reverting over time which is commensurate to empirical evidence. The result is that possibly there can be long periods with above average inflation rates and below average inflation rates. Further, expected inflation rates and interest rates are correlated which is in line with empirical evidence.

\subsection{Calibration of the Asset Model}

We use maximum likelihood estimation to calibrate the model parameters to monthly total return data of the MSCI World performance index, German zero bond spot rates with maturities $\tau=1,2, \ldots, 10$ years, and the consumer price index from January 1975 to December 2004 (360 observations). The results of the estimation are reported in Table I. By using the MSCI World performance index we assume that the portion of funds invested in stocks is internationally diversified. The filtration of the short-rate and expected inflation is done by applying the Kalman Filter (Figure (1) $)^{5}$ We set the modified duration of the bond portfolio to $D=4.5$ so that the expected excess return $\lambda_{r} \sigma_{B}$ is 1.3 percent and volatility $\sigma_{B}=D \sigma_{r}$ is 3.9 percent. The expected stock excess return $\lambda_{S} \sigma_{S}$ and the volatility $\sigma_{S}$ are 5.9 and 15.8 percent, respectively. As expected, the correlation between the expected inflation rate and the interest rate is significant

\footnotetext{
${ }^{5}$ For the application of the Kalman Filter to the calibration of the Vasicek model we use the approach of Babbs and Nowman (1999).
} 


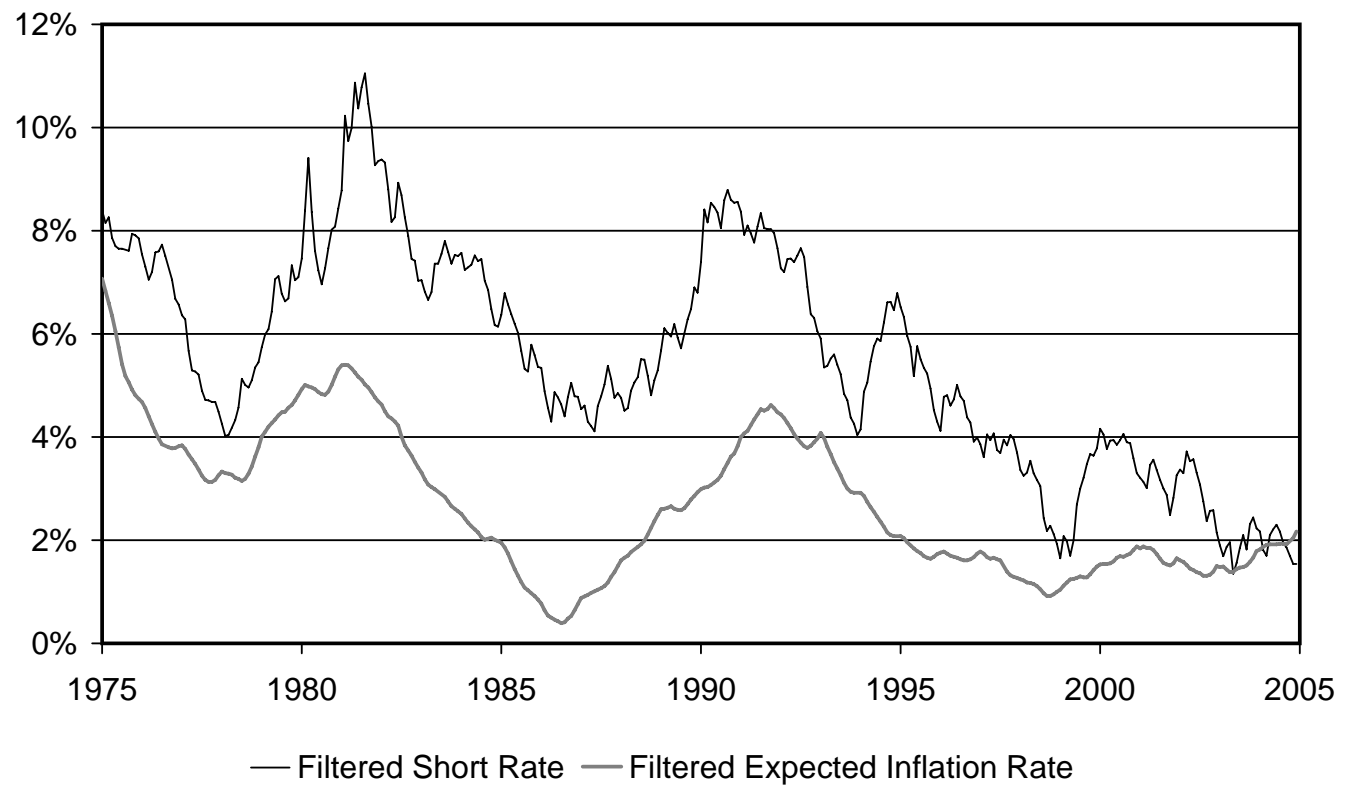

Figure 1: Filtered Short Rate and Expected Inflation Rate. The figure exhibits the filtered annualized short rate and inflation rate computed with the Kalman filter. The estimation uses monthly data from January 1975 to December 2004 (360 observations). Historical data about the interest rate term structure with maturities $\tau=1,2, \ldots, 10$ years and the development of the consumer price index in Germany are taken from the website from the German Central Bank (Bundesbank).

with 57.8 percent. The estimated long run mean of the expected inflation rate $\theta_{i}$ is 2.4 percent while the long run mean of the nominal short rate is 4.44 percent so that the real short rate is on average around 2 percent.

\section{Optimal Life-Cycle Strategy}

\subsection{The Wealth Evolution}

Having described the risk factors of the economy, we now turn to the evolution of retirement wealth. We assume that the investor can invest in the stock market, a bond portfolio with duration $D$, and the money market. The process of the of the plan 
Table I

Kalman Filter Estimates of Asset Model Parameters (in Percent)

\begin{tabular}{cccccccccccc}
\hline \multicolumn{2}{c}{ Stocks } & \multicolumn{2}{c}{ Bonds } & \multicolumn{2}{c}{ Interest Rates } & Inflation & \multicolumn{4}{c}{ Correlations } \\
& \multicolumn{3}{c}{$(D=4.5)$} & & & & & $S$ & $r$ & $Q$ & $i$ \\
\hline$\lambda_{S} \sigma_{S}$ & 5.80 & $\lambda_{r} \sigma_{B}$ & 1.30 & $\theta_{r}$ & 4.44 & $\theta_{i}$ & 2.40 & 1 & -5.31 & -6.75 & 0.26 \\
$\sigma_{S}$ & 13.58 & $\sigma_{B}$ & 3.87 & $\sigma_{r}$ & 0.86 & $\sigma_{i}$ & 1.30 & & 1 & 5.16 & 52.48 \\
& & & & $\kappa_{r}$ & 8.07 & $\kappa_{i}$ & 47.4 & & & 1 & 16.41 \\
& & & & $\lambda_{r}$ & 33.54 & $\sigma_{Q}$ & 1.01 & & & & 1 \\
\hline
\end{tabular}

Note. This table reports the (annualized) estimates for the stochastic processes of stocks, bonds, interest rates and inflation. The estimation uses monthly data from January 1975 to December 2004 (360 observations). As a proxy for the stock portfolio we use the return series of the MSCI World performance index. Historical data about the interest rate term structure and the development of the consumer price index in Germany are taken from the website from the German Central Bank (Bundesbank).

member's nominal wealth is

$$
d F_{t}^{n}=\left(r_{t}+\pi_{t}^{\prime} \sigma \lambda\right) F_{t}^{n} d t+\pi_{t}^{\prime} \sigma F_{t}^{n} d Z_{t}+c_{t} d t
$$

where $\lambda=\left(\lambda_{S} \lambda_{r}\right)^{\prime}$ is the vector of market prices of risk, $\sigma$ results from the Cholesky decomposition $\Sigma=\sigma \sigma^{\prime}$, and $d Z_{t}=\left(d Z_{t}^{S}-d Z_{t}^{r}\right)^{\prime}$. The vector of risky asset portfolio weights at time $t$ is denoted by $\pi_{t}=\left(\pi_{t}^{S} \pi_{t}^{B}\right)^{\prime}$, where $\pi_{t}^{S}$ and $\pi_{t}^{B}$ reflect the fraction of retirement wealth invested in stocks and bonds, respectively. Accordingly, the fraction invested in the money market is given by $\pi_{t}^{C}=1-\pi_{t}^{\prime} 1$. The investor continuously contributes a deterministic amount $c_{t}$ to the retirement wealth account. We assume that the contribution is 4 percent of a typical employee's current earnings.$^{6}$ To this end, the average earnings profile of an average German employee with vocational training (Figure (2)) is taken from Fitzenberger et al. (2001). Further, we assume that the term structure of nominal income rises at 2 percent per year. This increase in nominal income is chosen conservatively in the way that it compensates for the average increase of the price level. We abstract from stochastic fluctuations of contributions in order to

\footnotetext{
${ }^{6}$ The size of 4 percent is based on German regulations of funded individual retirement accounts (called Riester accounts) which require that from 2008 on 4 percent of income has to be contributed in order to become eligible for the entire tax subsidies.
} 


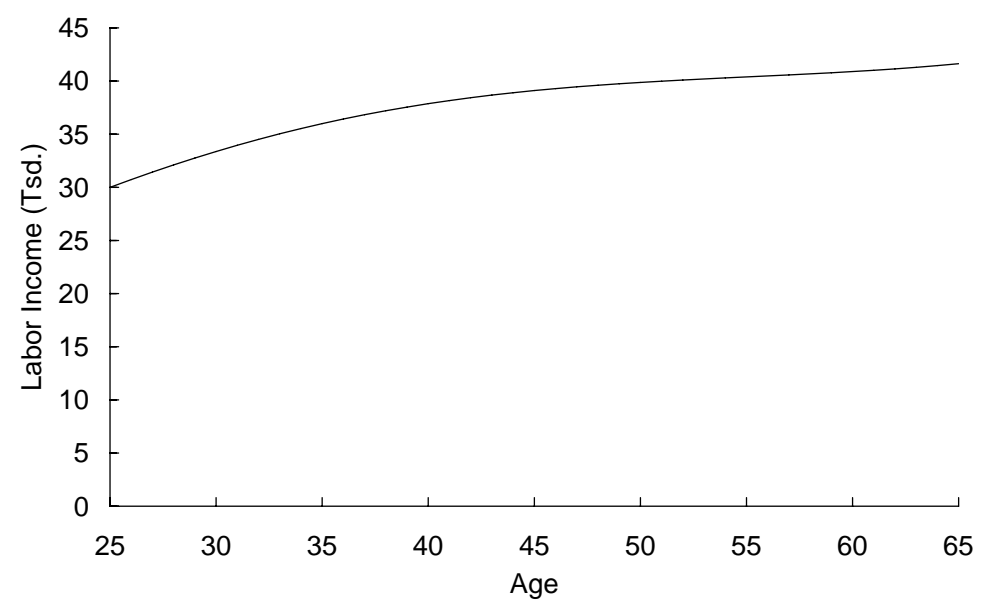

Figure 2: Average Life-Cycle Earnings Profile. The profile is taken from Fitzenberger et al. (2001) for employees without high school degree but with formal vocational training. Earnings at age 25 are set to 30 thousand EUR per year which is in the line with the average earnings of German employees according to the income survey from the Federal Statistical Office of Germany in 2005.

focus on the investment return risks. Cocco, Gomes, and Maenhout (2005) report that utility costs from ignoring labor income risk are small since the main effect remains in the discounting of future labor income. The investor's nominal augmented wealth $W_{t}^{n}$ consists of the financial wealth $F_{t}^{n}$ and the present value of future contributions $H_{t}^{n}$. The latter is given by

$$
H_{t}^{n}=\int_{t}^{T} c_{s} P(t, s-t) d s
$$

where $P(t, s-t)$ is the price of a zero coupon bond in $t$ with maturity $\tau=s-t$ from equation (6). Hence, the present value of future contributions is equal to a coupon bond with duration $D_{H, t}=\int_{t}^{T} c_{s} \frac{\partial P(t, s-t)}{\partial r_{t}} d s$ and dynamics

$$
d H_{t}^{n}=\left(r_{t}+\sigma_{H, t} \lambda_{r}\right) H_{t}^{n} d t-\sigma_{H, t} d Z_{t}^{r}-c_{t} d t,
$$


where $\sigma_{H, t}=D_{H, t} \sigma_{r}$ is the instantaneous volatility. Finally, the dynamics of augmented wealth after inflation $W_{t}^{r}$ are given by

$$
\begin{aligned}
d W_{t}^{r}=W_{t}^{r} & \left\{\frac{F_{t}^{r}}{W_{t}^{r}}\left(\left(r_{t}+\pi_{t}^{\prime} \sigma \lambda-\pi_{t}^{\prime} \sigma \sigma_{Q}\left(\rho_{S Q}-\rho_{r Q}\right)^{\prime}\right) d t+\pi_{t}^{\prime} \sigma d Z\right)\right. \\
& +\frac{H_{t}^{r}}{W_{t}^{r}}\left(\left(r_{t}+\sigma_{H, t} \lambda_{r}-\sigma_{Q} \sigma_{H, t} \rho_{r Q}\right) d t-\sigma_{H, t} d Z_{t}^{r}\right) \\
& \left.+\left(\left(-i_{e, t}+\sigma_{Q}^{2}\right) d t-\sigma_{Q} d Z_{t}^{Q}\right)\right\} .
\end{aligned}
$$

Apparently, investors can only control the dynamics of real augmented wealth $W_{t}^{r}$ by aligning the asset allocation $\pi_{t}$ of the financial wealth fraction $\frac{F_{t}^{r}}{W_{t}^{r}}$, while the dynamics of the present value of future contributions $H_{t}$ evolve completely exogenously. Since $H_{t}^{r}$ evolves like a coupon bond, the overall stock fraction of $W_{t}^{r}$ is $\pi_{t} \frac{F_{t}^{r}}{W_{t}^{r}}<\pi_{t}$. In turn, if investors desire an $x$ percent overall stock fraction they have to hold, $\pi_{t}=x \frac{W_{t}^{r}}{F_{t}^{r}}$ percent inside financial wealth. Over time the fraction $\frac{F_{t}^{r}}{W_{t}^{r}}$ converges to 1 so that the financial wealth stock fraction $\pi_{t}$ decreases to $x$.

\subsection{Optimal Benchmark Strategy}

We assume that the individual preferences are described by a utility function of the constant relative risk aversion class which can be expressed as:

$$
u\left(W_{t}^{r}\right)=\frac{\left(W_{t}^{r}\right)^{1-\gamma}}{1-\gamma}, \quad \gamma>0, \gamma \neq 1
$$

where $\gamma$ is the individuals coefficient of relative risk aversion (RRA) and $T$ the length of the investment horizon which is defined as the retirement age 65 minus the age at which the investor starts to contribute to the pension plan. We will consider investment horizons of 10, 20, 30, and 40 years, which corresponds to investors starting the accumulation plan at age $55,45,35$, and 25 , respectively. Note, that at time $T$ the value of future contributions is 0 , so that $W_{T}^{r}=F_{T}^{r}$. 
Since we prevent the portfolio strategy from varying according to the evolution of state variables, we cannot rely on the standard dynamic asset allocation approach in the spirit of Merton $(1969,1971)$. Rather than maximizing the drift of the value function conditional on the current state of nature, we construct the static life-cycle strategy by deriving the optimal weights $\pi_{t}$ which maximize the utility drift at each future point in time given the information at $t=0$ :

$$
\pi_{t}=\arg \max E_{0}\left[d u\left(W_{t}^{r}\right)\right]
$$

subject to the intertemporal budget restriction (13). The rationale is that maximizing the expected utility drift should deliver high terminal utility, as can be seen in the numerical results of the following section. The advantage of our approach is that the solution of the optimal asset allocation policy can be derived iteratively for increasing $t$. Otherwise it would be necessary to numerically compute the optimal asset allocation for all dates simultaneously. Due to the extremely high number of choice variables (number of dates $\times($ number of assets -1$))$ the latter approach can easily become numerically instable. To derive the optimal portfolio strategy we need terms of $E_{0}\left[d u\left(W_{t}^{r}\right)\right]$ depending on $\pi_{t}$ formed via an application of Ito's Lemma:

$$
\pi_{t}^{\prime} \sigma\left\{\left(\lambda-\sigma_{Q}\left(1-\frac{1}{2} \gamma\right)\left(\begin{array}{c}
\rho_{S Q} \\
\rho_{-r Q}
\end{array}\right)\right) E_{1, t}+\frac{1}{2} \gamma \sigma_{r}\left(\begin{array}{c}
\rho_{S r} \\
-1
\end{array}\right) E_{2, t}\right\}-\frac{1}{2} \gamma \pi_{t}^{\prime} \sigma \sigma^{\prime} \pi_{t} E_{3, t}
$$

with

$$
E_{1, t}=E_{0}\left[\frac{F_{t}^{r}}{\left(W_{t}^{r}\right)^{\gamma}}\right], \quad E_{2, t}=E_{0}\left[D_{H, t} \frac{F_{t}^{r} H_{t}^{r}}{\left(W_{t}^{r}\right)^{\gamma+1}}\right], \quad E_{3, t}=E_{0}\left[\frac{\left(F_{t}^{r}\right)^{2}}{\left(W_{t}^{r}\right)^{\gamma+1}}\right] .
$$


Computing the first order conditions and solving for the optimal portfolio weights yields

$$
\pi_{t}^{*}=\frac{1}{\gamma E_{3, t}}\left(\sigma^{\prime}\right)^{-1}\left\{\left(\lambda-\sigma_{Q}\left(1-\frac{1}{2} \gamma\right)\left(\begin{array}{c}
\rho_{S Q} \\
\rho_{-r Q}
\end{array}\right)\right) E_{1, t}+\frac{1}{2} \gamma \sigma_{r}\left(\begin{array}{c}
\rho_{S r} \\
-1
\end{array}\right) E_{2, t}\right\}
$$

For the calculation of the expectations $E_{1, t}, E_{2, t}$, and $E_{3, t}$ we perform Monte-Carlo simulations given the optimal weights for all points in time $s$ with $s<t$. In case the semi-analytical solution (16) exhibits short positions, we optimize (14) numerically given the short-selling restrictions $\pi^{S}, \pi^{B}, \pi^{C} \geq 0$. We restrict the investor from shortselling, since households are usually not allowed to borrow excessively against future labor income in order to purchase stocks. Figure (3) illustrates the optimal asset allocation schemes for risk aversions $\gamma=3$ (low risk aversion), $\gamma=5$ (moderate risk aversion), and $\gamma=10$ (high risk aversion) which should present a broad range of risk aversion. For example, Mehra and Prescott (1985) suggest that $\gamma=10$ is the highest reasonable risk aversion for investors. We plot the asset allocation schemes for investment horizons of $10,20,30$, and 40 years which corresponds to investors starting the accumulation plan at age $55,45,35$, and 25 years.

The optimal static life-cycle strategy clearly supports popular advice to reduce the equity fraction as one gets older, hence it conforms to recent life-cycle asset allocation studies (e.g. Cocco, Gomes, and Maenhout, 2005) and to life-cycle rules suggested by financial advisors or finance books (Malkiel, 1996). All scenarios exhibit a high initial stock fraction of 100 percent and a reduction of (relative) stock holdings over time. For the case $\gamma=3$, the optimal equity fraction drops to 85 percent just before the pension plan expires. Contrary, if the low risk strategy $(\gamma=10)$ implies that the equity exposure drops much earlier to about 25 percent.7 Figure (3) also reveals that not only the current age determines the optimal stock fraction, but also the age at which the investor started the pension plan. For instance, the optimal stock fraction of a 45

\footnotetext{
${ }^{7}$ For $\gamma=1$ and $\gamma=2$ the optimal fractions are 100 percent for the entire investment horizon.
} 

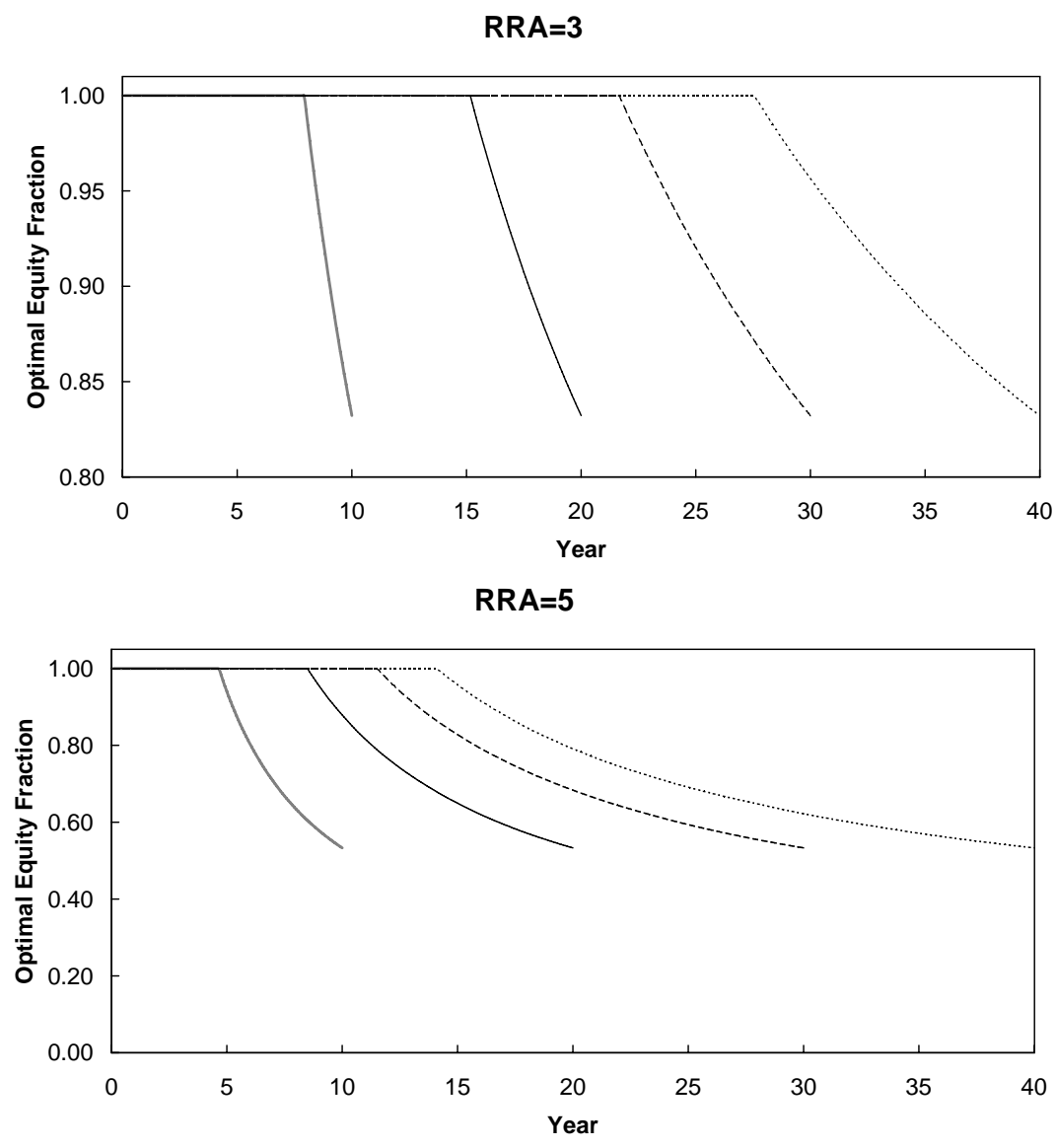

RRA $=10$

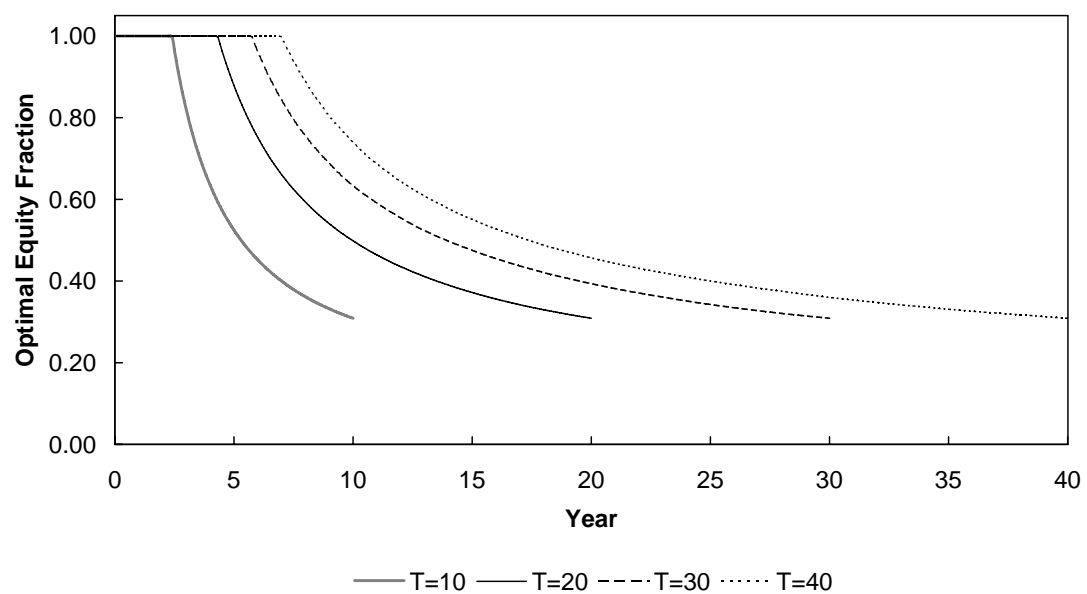

Figure 3: Optimal Equity Fraction for Various Risk Aversions and Durations. Each panel plots the optimal equity fraction for defined contribution plans with 10, 20, 30, and 40 years of duration. Each panel reports the results for a specific risk aversion $(\gamma=3,5,10)$. The calculation of the portfolio weights is done based on equation (16). The expectations in equation (15) are calculated iteratively via 20,000 Monte Carlo runs in which we set the time step to 1 month. 
year old investor with $\gamma=5$ is 100 percent if he just started the 20 year pension plan (dark solid line) but it would be around 50 percent if he started the plan with age 25 (dotted line). In all cases, except $\gamma=10$ the remaining wealth is just invested in bonds $\left(\pi_{t}^{B}=1-\pi_{t}^{S}\right)$. In case $\gamma=10$ the cash quote $\pi_{t}^{C}$ increases over time to 4 percent.

The reason for the declining equity fraction is that the investors wealth is composed of the financial wealth $F_{t}^{r}$ and the discounted present value of future contributions $H_{t}^{r}$ . The investor views future contributions to the portfolio as a bond investment with declining value over time. Accordingly, it is optimal to start with high stock positions at early ages to compensate for the illiquid overinvestment in bond-like future contributions and to phase down the equity fractions later, so as to maintain the optimal stock fraction of total wealth (which includes the present value of bond-like future contributions) ${ }^{8}$ Another intuitive explanation is that the investor can easily compensate potential stock market downturns in the early phase of the accumulation plan because the sum of invested contributions is rather small compared to sum of contributions still to be made.

\section{Monte Carlo Analysis}

\subsection{Impact of Risk Aversion, Maturity, and Inflation on Op- timal Retirement Wealth and Replacement Ratios}

In order to make projections of possible outcomes of real terminal wealth when following the optimal life-cycle asset allocation rules derived above, we run 20.000 independent simulations. The time-step in these simulations is set to one month so that contributions and changes in the portfolio composition are made monthly.

Table II reports the dispersion of optimal terminal wealth measured as a multiple

\footnotetext{
${ }^{8}$ Stock investments would even be highly leveraged if we did not include the short-selling restrictions. So, the restriction to maximum stock fraction of 100 percent is strongly binding.
} 
of the sum of contributions made before and after inflation. These are the relevant figures for an potential investor to determine, first, when he should start contributing to a pension plan in order to achieve a certain level of retirement wealth and, second, to find out which grade of outcome dispersion he tolerates in order to determine his degree of risk aversion and to choose the appropriate static life-cycle strategy.

The longer the investment horizon the higher each percentile of terminal wealth due to the compound interest effect. However, the increase is steeper for high percentiles than for low percentiles so that the outcome dispersion also increases. This effect is particularly driven by the rising skewness of compounded stock returns. Furthermore, the relative difference between percentiles before and after inflation grows with the length of the investment horizon so that it becomes in turn more important to account for inflation for long investment horizons.

In addition to the investment horizon, the level of risk aversion has considerable impact on the dispersion of terminal wealth since it determines the magnitude of the optimal stock market exposure. For instance, for $\gamma=10$ the range of growth rates lies between 5.75 (95th percentile) and 1.76 (5th percentile) after inflation for $T=40$, but for $\gamma=1$, the 95 th percentile (16.88) is 10 times higher than the 5th percentile (1.70). The significant impact of the asset allocation on the characteristics of terminal wealth suggests how important it is to estimate the risk aversion of the private investor accurately in order to provide him with the adequate pension plan asset allocation.

It is also illustrative to know how high the additional private pension is given that the terminal wealth is converted into a life-long annuity. To this end, we assume in the following analysis that the terminal wealth is used to purchase a nominal life-annuity with escalating payouts..$^{9}$ The premium $a(65, T)$ for an annuity with an initial payout

\footnotetext{
${ }^{9}$ The empirical relevance of inflation indexed annuities varies when considering different countries. The U.S. private annuity market practically offers only nominal annuities whereas the real annuity market in U.K. is well developed (see Brown, Mitchell, Poterba, 2001).
} 
Table II

Percentiles of Optimal Terminal Wealth Growth Rates

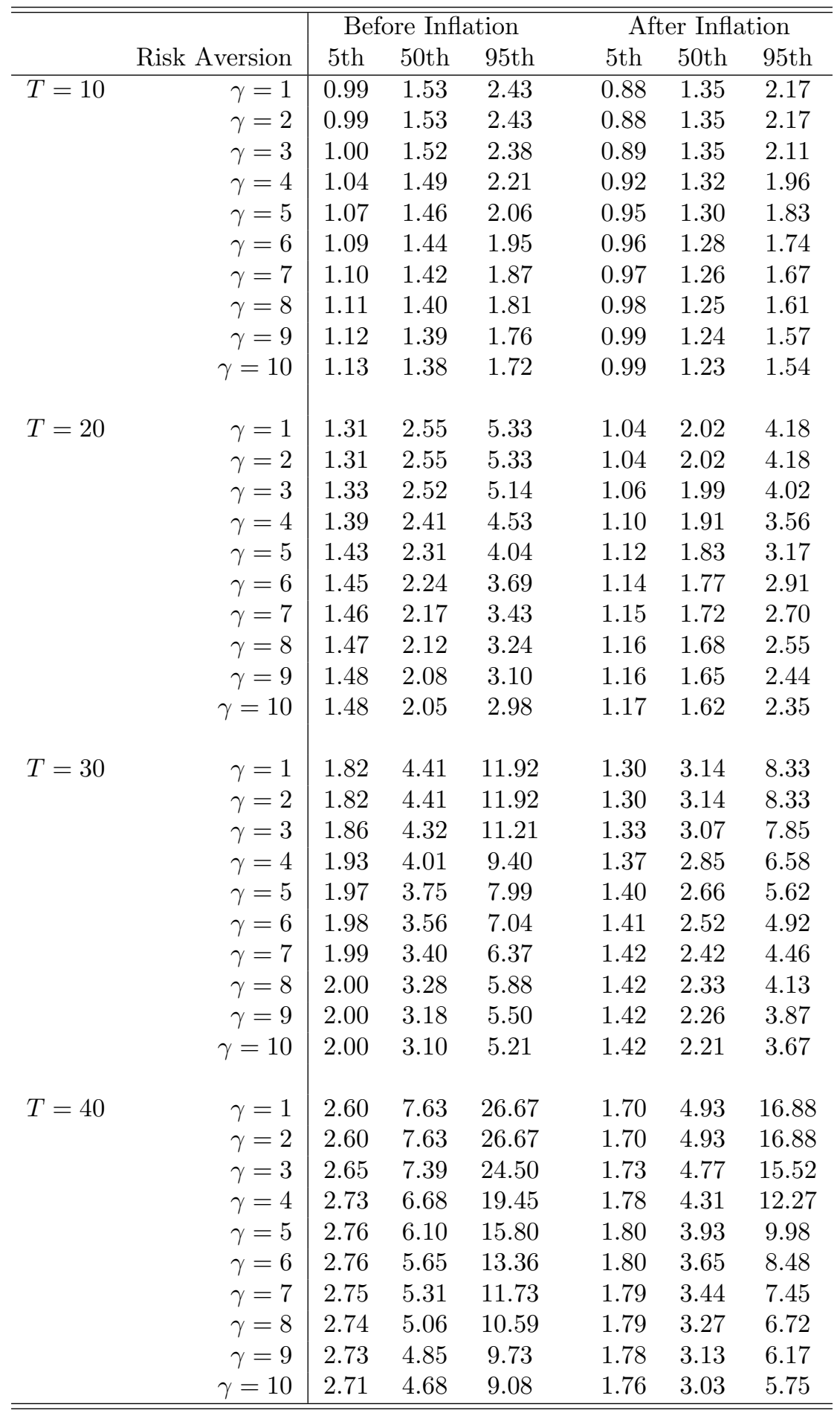

Note.This table presents the 5th, 50th, and 95th percentile of wealth growth-rates before and after inflation for varying risk aversion $\gamma$ and investment horizons $T$. The computation is done using the parameters given in Table 1 and simulation of 20,000 trajectories for the different optimal defined contribution plans. The optimal portfolio weights are calculated according to equation (16). 
of 1 for a 65 year old individual at time $T$ is calculated actuarially fair according to

$$
a(65, T)=\sum_{s=0}^{\infty} p(65, s)(1+\delta)^{s} P(T, s)
$$

where $p(65, s)$ is the probability that the retiree survives to age $65+s$ given that he is alive at age 65 and $(1+\delta)$ is the annual growthrate of annuity payments. Survival probabilities are taken from the DAV 2004 Aggregate 1 mortality tables for females with trend adjustment to account for mortality improvements. We set $\delta=0.02$ which is approximately commensurate to expected inflation. This parameterization ensures that the real income from annuities during retirement is flat in expectation. The conversion of nominal terminal wealth $W_{T}^{n}$ leads to an initial nominal annuity income of $W_{T}^{n} / a(65, T)$. We divide this income by the last pre-retirement labor income in order to calculate the so-called replacement ratio which is a commonly used measure to assess which labor income drop the retiree can compensate.

The range of simulated replacement ratios for various risk aversions and investment horizons appears in Table III. Together with the level of replacement ratios, the variability of outcomes rises drastically over time. While the low risk strategy $\gamma=10$ produces outcomes which lie between 2.3 (5th percentile) and 4.17 percent (95th percentile) for $T=10$, corresponding values for $T=40$ are 16.8 (5th percentile) and 65.9 percent (95th percentile). The increase is amplified even further for the high risk strategy, so that the replacement ratio at the 95th percentile is more than ten times higher than the one at the 5 th percentile (190.2 versus 16.1 percent). Since most private investors do not now which $\gamma$ they have, Table III is useful to assess how long and how risky one should invest in order to attain a certain additional income during retirement with a certain probability. The probable minimum replacement ratio (5th percentile) is an important indicator if the investor needs a certain additional income with high confidence. For instance, if the investor needs an additional pension income of 16 percent he has to start accumulating at age 25 (i.e. $T=40$ ). This will ensure that he reaches his 
Table III

Percentiles of Optimal Replacement Ratios

\begin{tabular}{lrcccccc}
\hline \hline & \multicolumn{3}{c}{$T=10$} & & & \multicolumn{3}{c}{$T=20$} \\
& 5 th & 50 th & 95 th & & 5 th & 50 th & 95 th \\
\hline$\gamma=1$ & 2.07 & 3.38 & 5.73 & $\gamma=1$ & 5.07 & 10.46 & 23.62 \\
$\gamma=2$ & 2.07 & 3.38 & 5.73 & $\gamma=2$ & 5.07 & 10.46 & 23.62 \\
$\gamma=3$ & 2.10 & 3.36 & 5.62 & $\gamma=3$ & 5.15 & 10.34 & 22.73 \\
$\gamma=4$ & 2.17 & 3.29 & 5.23 & $\gamma=4$ & 5.34 & 9.91 & 20.05 \\
$\gamma=5$ & 2.23 & 3.24 & 4.91 & $\gamma=5$ & 5.48 & 9.52 & 17.93 \\
$\gamma=6$ & 2.26 & 3.19 & 4.68 & $\gamma=6$ & 5.56 & 9.19 & 16.43 \\
$\gamma=7$ & 2.29 & 3.14 & 4.49 & $\gamma=7$ & 5.61 & 8.92 & 15.34 \\
$\gamma=8$ & 2.31 & 3.11 & 4.36 & $\gamma=8$ & 5.64 & 8.71 & 14.53 \\
$\gamma=9$ & 2.32 & 3.08 & 4.25 & $\gamma=9$ & 5.65 & 8.55 & 13.90 \\
$\gamma=10$ & 2.33 & 3.06 & 4.17 & $\gamma=10$ & 5.66 & 8.41 & 13.41 \\
& & & & & & & \\
\hline & & $T=30$ & & & & $T=40$ & \\
& 5 th & 50 th & 95 th & & 5 th & 50 th & 95 th \\
\hline$\gamma=1$ & 9.58 & 24.72 & 71.78 & $\gamma=1$ & 16.21 & 50.77 & 190.20 \\
$\gamma=2$ & 9.58 & 24.72 & 71.78 & $\gamma=2$ & 16.21 & 50.77 & 190.20 \\
$\gamma=3$ & 9.77 & 24.20 & 67.81 & $\gamma=3$ & 16.52 & 49.19 & 176.17 \\
$\gamma=4$ & 10.11 & 22.47 & 56.56 & $\gamma=4$ & 17.08 & 44.38 & 140.12 \\
$\gamma=5$ & 10.31 & 21.02 & 48.29 & $\gamma=5$ & 17.25 & 40.50 & 114.28 \\
$\gamma=6$ & 10.40 & 19.88 & 42.56 & $\gamma=6$ & 17.25 & 37.59 & 96.54 \\
$\gamma=7$ & 10.41 & 19.04 & 38.53 & $\gamma=7$ & 17.19 & 35.48 & 84.94 \\
$\gamma=8$ & 10.42 & 18.37 & 35.68 & $\gamma=8$ & 17.09 & 33.75 & 76.75 \\
$\gamma=9$ & 10.40 & 17.83 & 33.45 & $\gamma=9$ & 16.97 & 32.32 & 70.60 \\
$\gamma=10$ & 10.37 & 17.38 & 31.73 & $\gamma=10$ & 16.82 & 31.18 & 65.93 \\
& & & & & & &
\end{tabular}

Note.This table presents the 5th, 50th, and 95th percentile of replacement ratios for various risk aversions $\gamma$ and investment horizons $T$. The replacement ratio is defined as the first annuity income divided by the last pre-retirement labor income whereby it is assumed that the terminal wealth is converted into a life-long escalating annuity. The computation is done using the parameters given in Table 1 and simulation of 20,000 trajectories for the different optimal defined contribution plans. The optimal portfolio weights are calculated according to equation (16).

goal with approximately 95 percent probability. On the other hand, an investor which already has a high and secure pension income from other sources (e.g. public pension or defined benefit plans) might not need to save as long and prefer a more risky strategy.

\subsection{Utility Costs of Suboptimal Strategies}

This section is devoted to the evaluation of the most common asset allocation schemes for defined contribution plans against the optimal strategy derived above. To this end, 
we consider the following asset five allocation schemes:

1. Pure stock/bond/money plans. Although those strategies do not gain from diversification among asset classes we introduce them in order to gain insight into the long term risk and return profile implied by the assumed model and parameterization of the three asset classes stocks, bonds, and money. Especially pure money plans are the most often default option offered in defined contribution plans if participants do not actively change the investment option (Holden and Venderhei, 2005).

2. Constant mix strategies. In the class of constant mix strategies we consider the $60 / 40$ stock bond mix. The upside of constant mix strategies is that they are easy to realize for the provider from an administration perspective if there already exists a mutual fund for each asset class.

3. Life-cycle strategies. We implement the strategy commonly known as the "100-minus-age" strategy which invests 100 - age percent in stocks and the remainder in bonds.

4. Static portfolio insurance. The common notion of portfolio insurance strategies is restrict the downside risk at the end of the pension plan. The usual guarantee is that at the end of the pension plan at least the sum of invested contributions is attained. We construct the strategy such that always as many zero coupon bonds as needed to maintain a nominal return guarantee are held in the portfolio. The part which is invested into zero bonds is exactly the present value of the money-back guarantee of the nominal contribution. Here the zero bonds have the same duration as the remaining pension plan maturity. This strategy is basically a cash-flow matching strategy and has the advantage that the minimum return guarantee is met with 100 percent probability.

5. Dynamic portfolio insurance. These portfolio insurance strategies dynamically control the stock fraction over time, usually such that at the end of the pension plan the value of the portfolio exceeds the sum of contributions (in nominal terms). We employ the famous constant proportion portfolio insurance strategy (CPPI) in which 
the stock fraction is set according to:

$$
\pi_{t}^{S}=\min \left(m \frac{F_{t}^{n}-B_{t}}{F_{t}^{n}}, 1\right)
$$

where $m$ is the so-called multiplier and $B_{t}$ is the present value of the sum of contributions made until $t$. We set the multiplier to 4 . Since we assume that the portfolio is balanced monthly, setting the multiplier to 4 implies that the assumed maximal loss of stock markets in one month is $1 / 4=25$ percent. The bond fraction is set to $1-\pi_{t}^{S}$. The motivation of this strategy is that in contrast to static portfolio insurance a certain probability to miss the nominal return guarantee is tolerated in order to increase the expected return. This, because static portfolio insurance strategies have to start from the beginning with a certain bond fraction in order to keep the money-back guarantee, the CPPI strategy starts out with a pure stock portfolio and switches to bonds only if the money-back guarantee is jeopardized. Hence, the risk and return profiles of both portfolio insurance strategies are fundamentally different, except for the fact that both have the goal to keep the money-back guarantee at the end of the investment horizon.

We assess the risk and return efficiency of the described strategies in terms of utility losses relative to the optimum. To this end, we calculate the certainty equivalent wealth for each considered strategy and compare it to that of the optimal strategy. The certainty equivalent wealth $(\mathrm{CEW})$ denotes the riskless terminal wealth in real terms which the individual needs to be indifferent between following a certain asset allocation strategy and earning the CEW. Formally, the CEW is defined by the condition

$$
u(C E W)=E\left[u\left(W_{T}^{r}\right)\right]
$$

Having calculated the CEW levels for the optimal strategies and the practicable investment plans we compute the relative difference between the CEW of the practicable strategies and that of the optimal strategy. Since the evaluation of the strategy heavily 

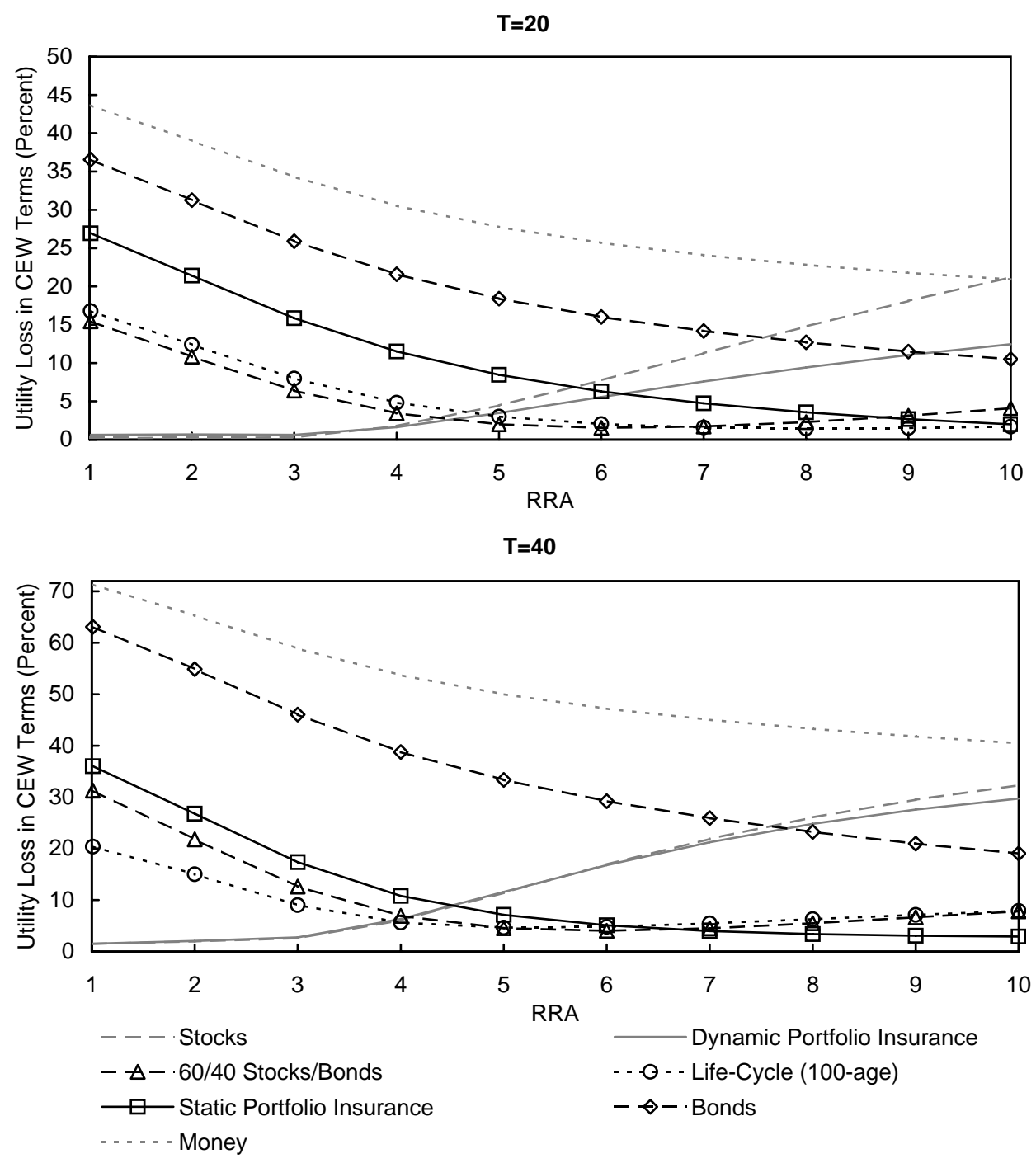

Figure 4: Relative Loss in Certainty Equivalent Wealth of Practicable Strategies Compared to the Optimum. This figure shows for various degrees of risk aversions the utility loss of following a suboptimal strategy compared to the optimal strategy. The calculation is done via Monte Carlo simulations (20,000 paths) for a defined contribution plans with the duration of $T=20$ (upper graph) and $T=40$ years (lower graph).

depends on the risk aversion parameter we calculate the relative loss in CEW for a range of risk aversions between $\gamma=1$ and $\gamma=10$.

The results of this analysis are reported in Figure (4) for the investment horizons $T=20$ and $T=40$. Conveniently, we identify three segments of risk aversion (low, moderate, and high). The upper graph displays the results for $T=20$. At very low 
degrees of risk aversion around $\gamma=1$ and $\gamma=2$ investors would prefer stock based investments like the pure stock plan and the dynamic portfolio insurance so that utility losses of that strategies are quite small. Utility losses of diversified strategies which mix asset classes like the constant mix, life-cycle, static portfolio insurance strategy would be around 20 percent. Holding a pure bond or money plan would lead to significant utility losses of around 40 percent. For moderate risk aversions in the range $\gamma=3$ to $\gamma=8$ the 100-minus-age rule and the constand mix strategy are closest to the optimum with utility losses below 10 percent. The stock based strategies lead already to high utility discounts up to 20 percent while the bond based strategy leads to losses of about 15 to 30 percent. The pure money market investment leads to high losses of more than 30 percent. For high risk aversions $\gamma=9$ to $\gamma=10$ the static portfolio insurance together with the 100-minus-age rule and the constand mix strategy become the preferred strategies with utility losses below 5 percent. In this high risk aversion segment stock based strategies lead to utility losses of around 25 percent, and similar results are obtained for pure money market plans. It is also noteworthy that the dynamic portfolio insurance and static portfolio insurance strategy exhibit fundamentally different risk profiles although both have the main goal to warrant the nominal moneyback guarantee. By and large, the pattern of results stays the same for $T=40$ (lower graph), except for that utility losses increase by about 20 percent for all strategies.

The analysis reveals that utility losses can be extremely high if investors choose a strategy which does not reflect their risk aversion. Utility losses can be especially high if the portfolio is underdiversified and only one asset class is held. Conversely, strategies which mix asset classes benefit from having a more moderate risk-return profile. In turn, if investors do not know their risk aversion exactly, diversified strategies should be preferred. They are most attractive to moderately risk averse investors and lead to small utility losses at the ends of the risk aversion spectrum. This result makes clear how crucial the estimation of the investor attitude towards risk is, particularly if the 
investment horizon is so long. Investment risks have to be clarified to the investor so that he can choose the most suitable portfolio strategy. Furthermore, the risk aversion parameter should reflect background risks of the individual, which can hardly been modeled explicitly. For instance, it might be necessary to adjust the risk aversion parameter in order to take into account other components of household wealth such as human capital, housing, and insurance wealth.

\section{Conclusions}

In the light of the disillusioning evidence on household financial literacy, the present paper has derived relatively simple optimal asset allocation rules which could serve as default options for defined contribution plans. To be practicable for pension plan providers we impose short selling restrictions and require the optimal asset allocation strategy to evolve deterministically over time rather than stochastically. From the view of plan participants this deterministic life-cycle strategy is transparent and easily comprehensible since they ex-ante know which asset allocation will be held at future dates. Further, performance losses due to administration as well as transactions costs can be avoided. Thereby, our assumed asset model accounts for the major long-term investment risks: stock market price risk, expected and unexpected inflation risk as well as interest rate risk.

Regarding the optimal asset allocation our results conform to recent studies including non-financial income inasmuch the equity fraction declines until the retirement phase is reached. The reason is that the present value of future contributions is perceived as a bond investment so that it is optimal to engage higher stock fractions in the beginning of the pension plan and to decrease the fraction commensurately to the decline in the present value of future contributions. The higher the risk aversion the faster declines the stock fraction. 
Our Monte Carlo analysis shows that the choice of the asset accumulation strategy and the length of the investment horizon have significant impact on the outcome of the accumulation plan and hence standard of living during retirement. Investors should definitely be aware of how long they should accumulate retirement wealth and how risky they should invest in order to achieve the appropriate dispersion of retirement wealth or annuity income if wealth is converted into a life-annuity.

Our final welfare analysis suggests that typical asset allocation schemes found in practice are close to the optimum in terms of certainty equivalent wealth comparisons if the scheme is chosen commensurately to the risk appetite of the plan participant so that utility losses are around 5 percent if the risk aversion of the participant is estimated correctly. However, if an asset allocation strategy is chosen that does no reflect the risk aversion of the investor, utility losses can reach up to 60 percent. Utility losses become particularly severe for longer investment horizons. 


\section{References}

Babbs, S., and K. Nowman, 1999, "Kalman Filtering of Generalized Vasicek-Term Structure Models," The Journal of Financial and Quantitative Analysis, 34 (1), 115130.

Barber, B., and T. Odean, 2000, "Trading Is Hazardous to Your Wealth: The Common Stock Investment Performance of Individual Investors," Journal of Finance, 55 (2), 773-806.

Beshears, J., J. Choi, D. Laibson, and B. Madrian, 2006, "The Importance of Default Options for Retirement Saving Outcomes: Evidence from the United States," Discussion paper, NBER, No. 12009.

Brandt, M., 1999, "Estimating Portfolio and Consumption Choice: A Conditional Euler Equations Approach," Journal of Finance, 54, 1609-1645.

Brennan, M., and Y. Xia, 2000, "Stochastic Interest Rates and Bond-Stock Mix," European Finance Review, 4, 197-210.

Brennan, M., and Y. Xia, 2002, "Dynamic Asset Allocation under Inflation," Journal of Finance, 57, 1201-1238.

Cairns, A., D. Blake, and K. Dowd, 2006, "Stochastic Lifestyling: Optimal Dynamic Asset Allocation for Defined-Contribution Pension Plans," Journal of Economic Dynamics and Control, 30, 843-877.

Campbell, J., Y. Chan, and L. Viceira, 2003, "A Multivariate Model of Strategic Asset Allocation," Journal of Financial Economics, 67, 41-80.

Campbell, J., and L. Viceira, 1999, "Consumption and Portfolio Decisions When Expected Returns are Time-Varying," Quarterly Journal of Economics, 114, 433-495. 
Campbell, J., and L. Viceira, 2001, "Who Should Buy Long-Term Bonds," The American Economic Review, 91, 99-127.

Carhart, M., 1997, "On persistence in mutual fund performance," Journal of Finance, $52,57-82$.

Cocco, J., F. Gomes, and P. Maenhout, 2005, "Consumption and Portfolio Choice over the Life Cycle," The Review of Financial Studies, 18, 491-533.

Fitzenberger, B., R. Hujer, T. MaCurdy, and R. Schnabel, 2001, "Testing for uniform wage trends in West-Germany: A cohort analysis using quantile regressions for censored data," Empirical Economics, 112, 41-86.

Holden, S., and J. Venderhei, 2005, "401(k) Plan Asset Allocation, Account Balances, and Loan Activity in 2004," Discussion paper, EBRI Issue Brief, No. 285, Investment Company Institute and Temple University.

Huberman, G., S. Iyengar, and W. Jiang, 2007, "Defined Contribution Pension Plans: Determinants of Participation and Contributions Rates," Journal of Financial Services Research, 31, 1-32.

Iyengar, S., and M. Lepper, 2000, "When Choice is Demotivating: Can One Desire Too Much of a Good Thing?," Journal of Personality and Social Psychology, 79, 995-1006.

Merton, R., 1969, "Lifetime Portfolio Selection under Uncertainty: The Continous Time Case," Review of Economics and Statistics, 51 (3), 239-246.

Merton, R., 1971, "Optimum Consumption and Portfolio Rules in a Continuous-Time Model," Journal of Economic Theory, 3 (4), 373-413.

Munk, C., C. Soerensen, and T. Vinther, 2004, "Dynamic asset allocation under meanreverting returns, stochastic interest rates, and inflation uncertainty: Are popular 
recommendations consistent with rational behavior?," International Review of Economics 83 Finance, 13, 141-166.

Poterba, J., J. Rauh, S. Venti, and D. Wise, 2005, "Lifecycle Asset Allocation Strategies and the Distribution of 401(k) Retirement Wealth," Discussion paper, NBER, No. 11974 .

Shafir, E., I. Simonson, and A. Tversky, 1993, "Reason-based Choice," Cognition, 49, $11-36$.

Shiller, R., 2005, "The Life-Cycle Personal Accounts Proposal for Social Security: An Evaluation," Discussion paper, Yale University.

Tversky, A., and E. Shafir, 1992, "'Choice Under Conflict: The Dynamics of Deferred Decision," Psychological Science, 3, 358-361.

van Rooij, M., C. Kool, and H. Prast, 2007, "Risk return preferences in the pension domain: are people able to choose?," Journal of Public Economics, 91, 701-722.

Vasicek, O., 1977, "An Equilibrium Characterization of the Term Structure," Journal of Financial Economics, 5, 177-188.

Viceira, L., 2007, "Life-Cycle Funds," Discussion paper, Harvard Business School.

Wachter, J., 2002, "Portfolio and Consumption Decisions Under Mean-Reverting Returns: An Exact Solution for Complete Markets," Journal of Financial and Quantitative Analysis, 37, 63-91.

Wachter, J., 2003, "Risk Aversion and Allocation to Long-Term Bonds," Journal of Economic Theory, 112, 325-333. 